\title{
Efficacy of Kshara Application in the Management of Internal Haemorrhoids-A Pilot Study
}

\author{
Bijendra Shah $^{1}$, Tukaram Sambhaji Dudhamal ${ }^{1}$ and Shivmangal Prasad ${ }^{2}$ \\ 1. Department of Shalya Tantra, Institute for Post Graduate Teaching and Research in Ayurveda, Gujrat Ayurveda University, \\ Jamnagar, Gujarat, Pin-361008, India \\ 2. Department of Kaumarbhritya Tribhuvan University, Kathmandu, A.P.O.- 44618, Nepal
}

\begin{abstract}
BACKGROUND: Ksharakarma (application of plant alkali) is a process of kshara (plant alkali) application called as pratisaraneeya kshara. It is a non-surgical procedure of Ayurveda indicated for the management of haemorrhoids. Kshara is alkaline in nature derived from a combination of various herbs that is applied to the pile mass with the help of a special slit proctoscope. Haemorrhoids are dilated veins within the anal canal in the sub-epithelial region formed by radicals of the superior, middle and inferior rectal veins. METHOD: 33 patients having haemorrhoids with complaints of mass protrusion, pain and bleeding per rectal of different grade (1st, 2nd, 3rd degree), irrespective of age, sex, religion and occupational status. Under local anaesthesia with $2 \%$ lignocaine hydrochloride Ksharakarma was done plant alkali of having strong potency of Achyaranthes aspera. Post procedure dressing was done with Jatyadi oil (Medicated Ayurved oil) and ayurvedic laxative was prescribed. RESULT: After 15 days, all major complaints i.e. mass protrusion got reduced, total score of pain before treatment was as visual analogue scale and after treatment was 0 and bleeding was also reduced. CONCLUSION: The result manifests that internal haemorrhoids can be treated with Ksharakarma having negligible recurrence rate.
\end{abstract}

Key words: Achyaranthes aspera, Jatyadi oil, kshara, ksharakarma, haemorrhoid.

\section{Introduction}

Ksharakarma is a process of Kshara application called as Pratisaraneeya kshara. It is a non-surgical procedure of Ayurveda indicated for the management of Arsha (Haemorrhoids). Kshara is alkaline in nature derived from a combination of various herbs that is applied to the pile mass with the help of a special slit proctoscope. Sushruta has described it as one of the best Para-surgical tool for the successful treatment of various surgical ailments [1]. Kshara are superior to the Shastra (surgery) and Anushastra (para-surgery) and due to its Tridoshaghna (power to alleviate all the three dosha (Bioelements)) properties to perform Chedana (excision), Bhedana (incision) and Lekhana (scrapping) [2]. It is a type of chemical cauterization. It destroys the unhealthy tissues and promotes healing process. Arsha

Corresponding author: Tukaram Sambhaji Dudhamal, M.S. (Ayu), Ph.D. (Ayurved), associate professor, research field: ayurveda surgery. is muscular enlarged mass in the three vali of guda (sub mucosa of anal canal). Ksharakarma procedure interpreted as "Potential cauterization Therapy" is the specific field taken in the present research work. Ksharakarma treatment is found to be suitable and acceptable as compared with the prevalent methods in medical science. The study has been planned with objective to catalogue the role of Ksharakarma in managements of 1st, 2nd and 3rd degree internal Haemorrhoids (Arsha).

\section{Materials and Methods}

2.1 Tikshna Apamarga Kshara: (Alkali of Achyranthes Aspera with Strong Potency)

The kshara was prepared according to classical protocol [1]. It contains Apamarga (Achyranthes aspera Linn.), Shukti (Pearl) powder, Citarak (Plumbago zeylanica Linn.), limestone, Shankha (conch). 


\subsection{Selection of Patients}

33 patients fulfilling the clinical criteria made for the diagnosis of Haemorrhoids (Arsha) were selected irrespective of their sex, religion, occupation, etc from the outpatient department (OPD) of Nepal Ayurvedic Panchakarma and Ksharsutra polyclinic, Kirtipur, Kathmandu Nepal.

\subsection{Criteria of Diagnosis}

Diagnosis was made on the basis of physical, $P / R$ examination i.e. Inspection, palpation and Proctoscopic examination.

\subsection{Investigation}

All Routine examination of blood, urine, stool and X-Ray were carried out.

\subsection{Inclusion Criteria}

Patients with age of (20-50 years) having internal piles of 1st, 2nd and 3rd degree were included in this study.

\subsection{Exclusion Criteria}

The patients of carcinoma rectum, hepatitis, heart diseases, 4th degree piles, external piles, inflamed prolapsed, thrombosed piles. Patients of tuberculosis and pregnant women were also excluded from study.

\section{Methodology}

In this study, 33 patients who underwent Ksharakarma for the treatment of piles for first time in the year 2014 to 2015. Among them, 29 patients Ksharkarma was done once and in 4 patients due to larger size of pile mass we did Ksharkarma twice. Clinical features of all patients were assessed weekly for four weeks. Every six month after treatment the inquiry was done by telephone about recurrence. Ksharakarma-Kshara application was done in operation theatre (OT) by adopting Trividha Karma (operative procedure) of Sushruta as mentioned below [1].

\subsection{Purva karma (Pre-operative)}

After taking written informed consent perianal part was painted with antiseptic solution. Patient was kept nil orally for at least 6 hour before the procedure. Injection Tetanus toxoid $(0.5 \mathrm{ml}) \mathrm{I} / \mathrm{M}$ was given and xylocain sensitivity test was performed in each patient. $\mathrm{I} / \mathrm{V}$ line is get opened.

\subsection{Pradhana Karma (Operative Procedure)}

After the patient was position in lithotomy on the operation table, local anaesthesia was given. The part was painted with antiseptic solution. The diseased part is exposed by special slit proctoscope and examined for site of pile (Fig. 1). The adjoining healthy region of these organs was covered with gauze piece to prevent the spread of Kshara on healthy tissue. The Kshara was applied on proposed lesion by spatula and was kept on piles mass up to the counting 100 that is $1-2$ minutes (Fig. 2).

\subsection{Paschat Karma (Post-Operative)}

As soon as the sign of Samyak dugdha (proper cauterization) appears, the Kshara is rapidly neutralized by acidic fluid that is lemon water. Later, on the cauterized part is washed out with distilled water. Jatyadi ghee was applied on the cauterized lesion and dressing was done. Patients were allowed to orally sip liquids after 6-8 hour of Ksharkarma and were shifted to normal diets. Later patients were advised for Avagha Sweda (sitz bath) with Sphatikadiyoga (Alum powder) (5g/sitting) up to 5-10 minutes with maintenance of equal warm water.

Tab. Gandhak rasayan (anti-inflammatory drug of ayurveda) $250 \mathrm{mg}$ three times, Tab. Sigru guggulu (antibacterial drug of Ayurveda) $1 \mathrm{gm}$ three times and dressing with $10 \mathrm{ml}$ Jatyadhi oil as (therapeutic enema) was given for 15 days to reduce pain, inflammation and promote healing.

\subsection{Criteria of Assessment}

All the signs and symptoms were assigned a score 


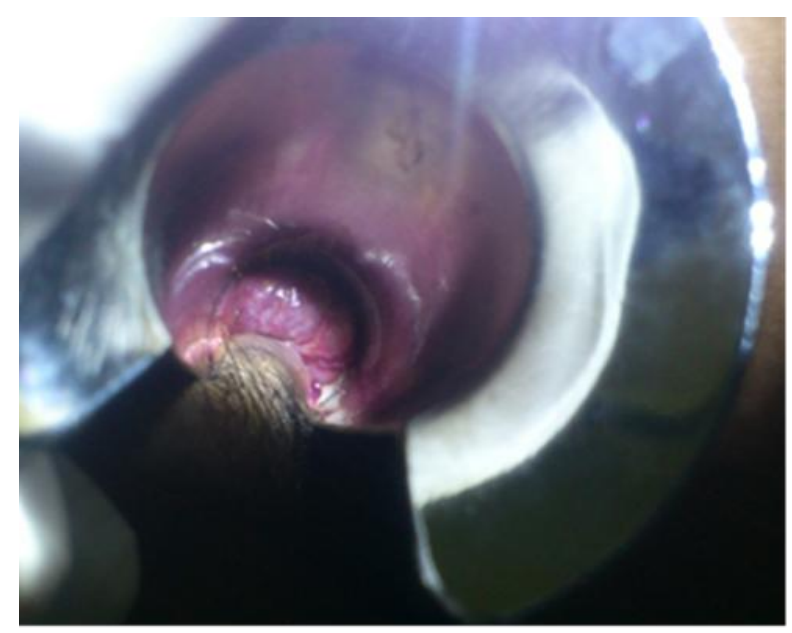

Fig. 1 Second degree piles before treatment.

depending as their severity to assess the effect of the procedure objectively. The following grading pattern was adopted for the scoring (Table 1).

\section{Observations and Results}

After Kshara application, all patients were followed up weekly for 4 weeks. During each follow-up visit relief in signs and symptoms were assessed. There was moderate to mild pain, tenderness, inflammation and brownish black discharge on first visit and second visit. During the third visit, there was no pain, tenderness, discharge or anal stricture and the internal hemorrhoids

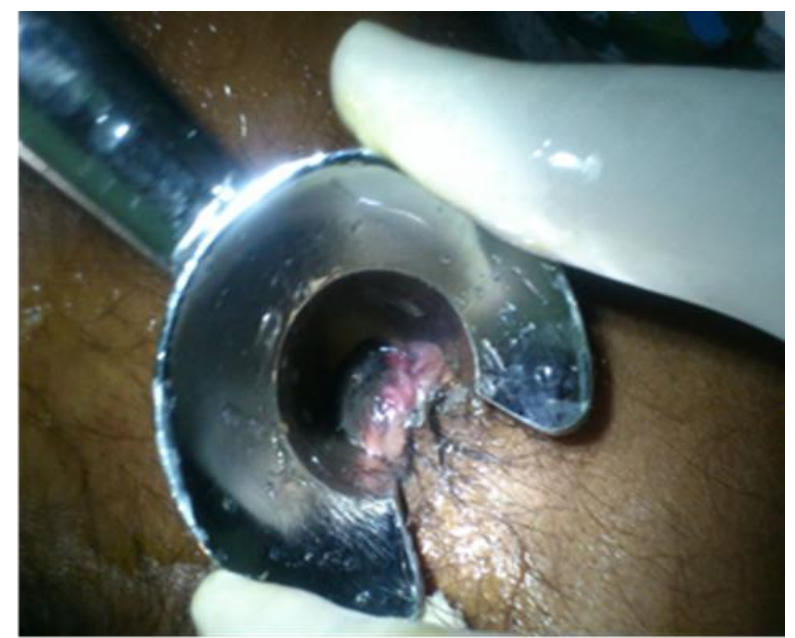

Fig. 2 After application of Kshara, pile became dark brown in colour.

had completely resolved (Table 2, Fig. 3). Ksharakarma shows significant improvement on clinical features of Arsha like rectal bleeding, pain in ano and constipation. In overall effect of therapy by Ksharakarma showed $69.7 \%$ of the patient got cured or complete remission of symptoms (Table 3). Average time taken for complete remission of pile mass was 21 days by Ksharakarma without bleeding, pain. Total effect of therapy on the basis of symptomatic relief to patients and observations of the Surgeon are depicted in the Table 4.

Table 1 Grading pattern.

\begin{tabular}{|c|c|c|c|}
\hline Grade & & Severity & Description \\
\hline \multirow{4}{*}{ Pain } & Grade-3 & Severe (VAS 9-10) & To relieve from pain, analgesic injection are required \\
\hline & Grade-2 & Moderate (VAS 5-8) & To relieve from pain, Oral analgesic are required \\
\hline & Grade-1 & Mild (VAS 1-4) & Feeling discomfort within tolerable limit, no required of analgesic \\
\hline & Grade-0 & Nil (VAS 0) & No discomfort in any manner in the site, no analgesic \\
\hline \multirow{4}{*}{ Bleeding } & Grade-3 & Severe & Changing sanitary pads or cotton pads minimum 2 times a day \\
\hline & Grade-2 & Moderate & Changing of pads once a day only \\
\hline & Grade-1 & Mild & No requirement of pad \\
\hline & Grade-0 & Nil & Area is completely dry \\
\hline \multirow{4}{*}{ Tenderness } & Grade-3 & Severe & $\begin{array}{l}\text { Patient feeling pain by touching perianal area. Not possible to perform } \\
\text { examination }\end{array}$ \\
\hline & Grade-2 & Moderate & Little finger P/R can be done, patient feeling very much tolerable pain \\
\hline & Grade-1 & Mild & Index finger P/R done with very much tolerable pain \\
\hline & Grade-0 & Nil & Index finger insertion to anal canal without any pain or discomfort \\
\hline
\end{tabular}


Table 2 Assessment of result.

\begin{tabular}{llll}
\hline Follow up visit & 1st visit (after 7 days) & 2nd visit (after 14 days) & 3rd visit (after 21 days) \\
\hline Total average of all & Moderate & Mild & Nil \\
Pus & Mild & Normal & Normal \\
Mucus & Mild & Mild & Normal \\
Blood & Mild & Normal & Normal \\
Itching & Mild & Mild & Mild (occasional) \\
Burning sensation & Moderate & Mild & Normal \\
Discharge & Mild & Mild & Normal \\
Sloughing & Mild & Mild & Normal \\
Tenderness & Moderate & Mild & Nil \\
Inflammation & Moderate & Mild & Nil \\
Discolouration & Red & Red & Colour of scar
\end{tabular}

Table 3 Effect of therapy.

\begin{tabular}{lll}
\hline Total Effect & No. of patients & Percentage \\
\hline Cured/complete remission & 23 & 69.7 \\
Marked Improvement & 5 & 15.1 \\
Improved & 3 & 9.1 \\
Absent in follow up & 2 & 6.1 \\
\hline
\end{tabular}

Table 4 Total effect of Ksharakarma.

\begin{tabular}{|c|c|c|}
\hline Days & Patient's complaints & Surgeon's observation \\
\hline $\begin{array}{l}1 \text { st day-Immediately after } \\
\text { Kshara application. }\end{array}$ & Mild pain, moderate burning sensation. & $\begin{array}{l}\text { Coagulation of haemorrhoid plexus, blackish } \\
\text { discolouration of mass looks like jambu phala } \\
\text { (Brownish Black colour). }\end{array}$ \\
\hline 2nd day & Pain, swelling. & $\begin{array}{l}\text { Edema and softening of coagulated mass, with } \\
\text { initiation of sloughing. }\end{array}$ \\
\hline 3 rd to 7 th day & $\begin{array}{l}\text { Blackish discharge, with tissues sloughing, pain, } \\
\text { burning sensation. }\end{array}$ & Sloughing, necrosis of mass. \\
\hline 8 th to 14 th days & $\begin{array}{l}\text { Mild to moderate burning sensation while passing } \\
\text { motion lasts for } 30 \text { minutes, stools mixed with few } \\
\text { drops of bleeding. }\end{array}$ & Mucosal ulcer on the site, mass get reduced on site. \\
\hline 15 th to 21 st days & No symptoms except mild discomfort like itching. & Healing of ulcer. \\
\hline After 21 days & No symptoms. & $\begin{array}{l}\text { Scar on the site with complete obliteration and } \\
\text { adhering of scar to muscular coat. }\end{array}$ \\
\hline
\end{tabular}

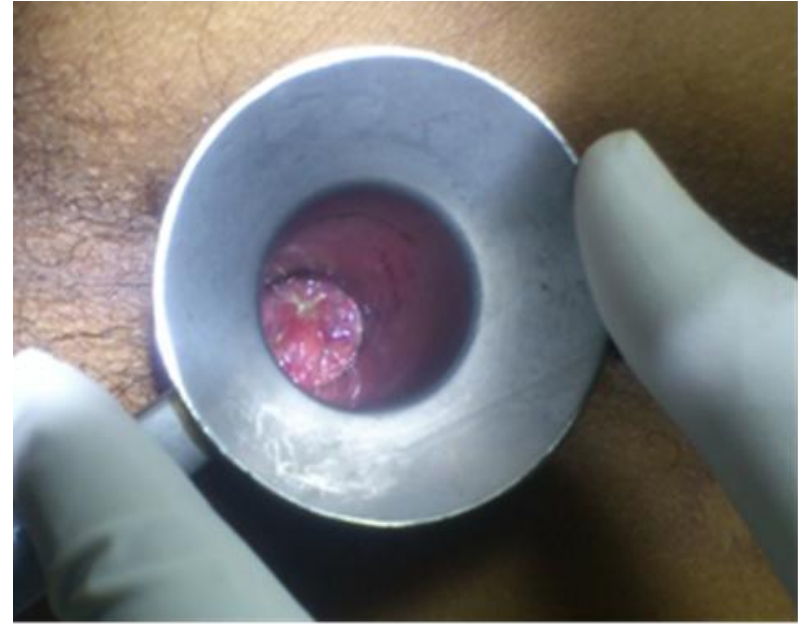

Fig. 3 Status of piles 21 days after Kshara application.

\section{Discussion}

Tikshna Apamarga kshara (alkali of Achyranthes aspera with strong potency) was applied to the 1st, 2nd and 3rd degree internal haemorrhoids (Arsha). It was observed that the pile mass became black in 60 seconds as described in the Sushruta Samhita [1, 2]. Lemon juice was used to neutralize the Kshara after proper burning of pile mass. The Kshara causes coagulation of the haemorrhoid plexus (cauterization of pile mass), necrosis of tissues followed by fibrosis of plexus, adhesion of mucosal, sub mucosal coat helps in prevention of further dilation of veins. It prevents 
relapse of regional mucosa of anus and makes permanent radical obliteration of haemorrhoids. During the oozing of blood, which is ceased by the sclerosing effect of the Kshara, it coagulates property of protein [3]. Hence there was no chance of bleeding during and after Kshara application. The chance of infection is least due to the sustained action of the anti-microbial property of Kshara [4]. Kshara acts as a fibrolytic agent which inhibits the growth of bacteria [2]. After application of Kshara patient was adviced to consult regularly on every week and they get feel much better in first week. Every day necrosis pile mass was reducing and after 21 days patients was free from all symptoms with normal scar. In four patients due to bigger size of pile mass we did Ksharakarma twice. There were not any complications observed during and after Kshara application. Along with Kshara application the adjuvant Ayurved drugs like Gandhak Rasayan helped to reduce the inflammation and minimize infection [5]. Sigru Guggulu is said to be antibacterial and anti-inflammatory which help to inhibit the bacterial infection [6]. Jatyadi oil is wound healing and soothing in nature which helped to heal the lacerated mucosa of piles and evacuation of feces smoothly [7]. Terminalia Chebula powder is laxative and helped to relief from constipation [8]. Now a day's application of Kshara is found to be safe, efficacious and cost effective method for management of internal 1st, 2nd and 3rd degree haemorrhoids. Ksharakarma procedure can be conducted at OPD level or can be performed with proper prophylactic measures. It is very effective procedure, no primary and reactionary haemorrhage is caused. It requires less time and patient can perform his/her routine work from next day of procedure. Antibiotic and anti-inflammatory drugs requirements are quite less. There is least possibility of recurrence. There is no adverse effect during the post-operative period, like anal stenosis/stricture, incontinence, bowel irregularities. Compilation of case reports and comparative clinical studies are needed to standardize the treatment protocol and catalogue outcome measures.

\section{Conclusion}

This study manifests that Tikshna Apamarga kshara was found effective in obliterating the 1st, 2nd and 3rd degree haemorrhoids (Arsha) mass. This study finally concluded that a combination of Ksharakarma, conservative treatment, diet restriction and life style modification administered over a period of minimum of 6 month is effective in obliterating the 1 st , 2 nd and 3rd degree pile mass as well as preventing recurrence on a long term basis.

\section{Acknowledgements}

Authors' special thanks are extended to the staff of Ayurveda Teaching Hospital-IOM, TU., AMDRF and NAPKC Kathmandu, Nepal.

\section{References}

[1] Acharya, J. T., and Acharya, N. R. 2013. Sushruta Samhita with Nibandhasangraha Commentary of Sri Dalhanacharya. Varanasi, India: Chokhambha Sanskrita Sansthan, 430. (in Sanskrit Indian)

[2] Prasad, L., Prakash, S., and Prakash, A. 2013. Colorectal Diseases and Kshar Sutra Surgery. New Delhi: Globalmedik a Health Science Publisher, 75.

[3] Kumar, P. H. 2011. Recent Trends in the Management of Arshas/Haemorrhoids. Delhi: Chokhambha Sanskrita Pratishthan, 39.

[4] Kumara, A. A. J. P., Jayaratne, D. L., and Anthony, D. J. 2016. "Antibacterial Activity of Pratisaraniya kshara (Achyranthes aspera) in the Management of the Fistula in Ano." International Journal of Ayurvedic and Herbal Medicine 6 (3): 2220-8.

[5] Hariprapanaji, P. 2004. Rasayogasagara, Varanasi: Choukhambha Krishnadas Academy, 364.

[6] Uttam, K., Shringi, M. K., Singh, N., and Urmale, R. 2015. "Role of shigru bija taila in abhighataj sopha w.s.r. to Traumatic Inflammation-A Clinical Study." IAMJ 3 (7): 1382-90.

[7] Dudhamal, T. S., Bhuyan, C., and Baghel, M. S. 2013. "Wound Healing Effect of Jatyadi Taila in the Cases of Chronic Fissure-in-ano Treated with Ksharasutra." AYU International Research Journal of Ayurved 34/5 (Suppl1) OA01:30: 22.

[8] The Ayurvedic Pharmacopeia of India. 2011. Delhi: The Controller Publication Civil Lines, 93. 